\title{
LABORATORY AND IN-SITU CHARACTERISATION OF MASONRY MATERIALS IN A LARGE HISTORICAL INDUSTRIAL BUILDING IN BARCELONA
}

\author{
ALBERT CABANÉ ${ }^{1 *}$, LUCA PELÀ $^{1}$ AND PERE ROCA ${ }^{1}$ \\ ${ }^{1}$ Department of Civil and Environmental Engineering \\ Universitat Politécnica de Catalunya (UPC-BarcelonaTech) \\ Jordi Girona 1-3, 08034 Barcelona, Spain \\ e-mail: albert.cabane@upc.edu, luca.pela@upc.edu,pere.roca.fabregat@upc.edu
}

Keywords: Masonry, MDT, Brick, Lime mortar, Core drilling, Compressive strength.

\begin{abstract}
This paper presents an experimental campaign carried out in an historical industrial building of Barcelona from the $19^{\text {th }}$ century, considering in-situ and laboratory minor destructive testing (MDT) techniques. The results obtained showed a good relationship between the in-situ MDT techniques and the tests carried out in the laboratory. The experimental results from different portions of the large-scale building allowed the discovery of different material typologies deriving from different construction phases.
\end{abstract}

\section{INTRODUCTION}

The determination of the mechanical properties of existing masonry structures faces significant difficulties due to the intrinsic complexity of this composite material. However, acquiring a full knowledge of the main parameters is necessary to design adequate conservation actions for the built cultural heritage [1]. The mechanical characterisation of existing masonry structures usually requires an optimum combination of laboratory and in-situ techniques, especially in large constructions. This research presents the experimental methodology applied to an extensive campaign carried out in an historical industrial building of Barcelona built in the $19^{\text {th }}$ century.

The experimental campaign resorted to minor destructive testing (MDT) techniques, both based on in-situ testing of masonry components and extraction of small samples for laboratory testing. The in-situ MDT allowed a preliminary evaluation of the variability of the properties over the large building in order to optimize the sampling and the execution of the laboratory tests. The results from different MDT techniques allowed useful cross-checking in order to keep a continuous control throughout the entire experimental program. The tests were developed on the units and mortar joints of both masonry walls and timbrel vaults, as well as on the plasters. 
The main objectives were to obtain a careful characterisation of the material components in order to evaluate their strength capacity and to choose compatible restoration materials of similar properties.

The in-situ experimental characterisation was carried out by means of the Pin Penetration Test (PPT) and the Helix Screw Pull-off Test (HPT) [2] on the mortar joints and bricks, as well as the PPT and Pull-off Test (POT) [3] on the mortar plasters. The experimental characterisation in the laboratory consisted in: compressive testing of small samples of bricks extracted from walls [4]; double punch testing (DPT) of mortar joints from the walls and the timbrel vaults; DPT of plaster specimens [5]; compressive testing of core drilled masonry (CDM) samples [6], [7]; and compressive testing of ceramic tile samples from the timbrel vaults by means of a novel nonstandard setup.

\section{FXPERIMENTAI PROGRAM IN-SITU}

\subsection{Windsor pin penetration test on mortar joints, bricks and plasters}

The pin penetration test (PPT) is a MDT method developed to evaluate in-situ the compressive strength of the concrete, mortars and bricks. A previous research [3] investigated how to adapt the test to historical lime mortar joints with a low compressive strength, as well as to historical fired clay bricks.
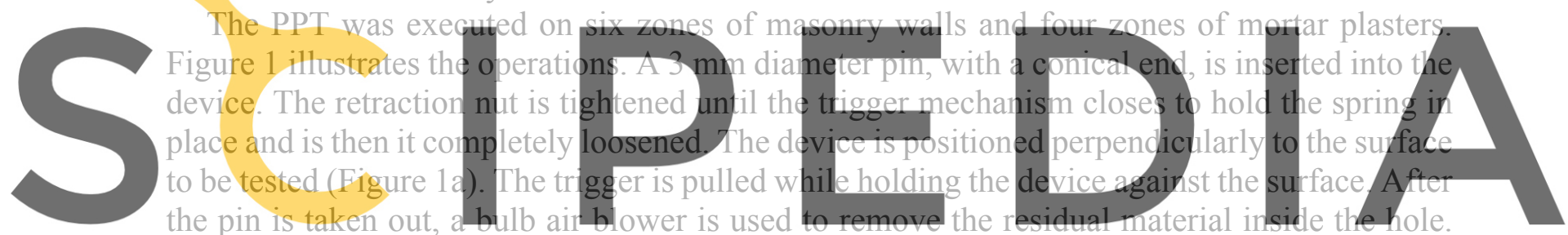
the pin is taken out, a bulb air blower is used to remove the residual material inside the hole.

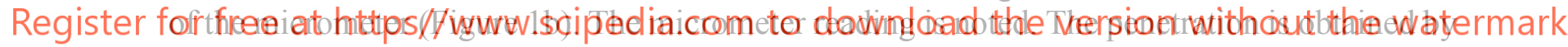
subtracting the reading from one inch $(25.4 \mathrm{~mm})$.
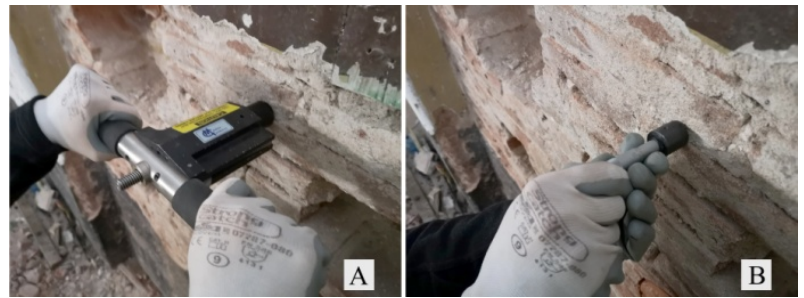

Figure 1: Pin Penetration Test operation: (A) the device is positioned perpendicularly to the surface to be tested, and, after firing the pin, (B) a micrometer is inserted to the bottom of the produced hole.

\subsection{Screw (helix) pull-out test on mortar joints and bricks}

The helix pull-out test (HPT) was carried out on the mortar joints and on the bricks. According to a previous research focusing on HPT in low strength mortars [3], a $3 \mathrm{~mm}$ diameter pilot hole was executed and preferred to the $4 \mathrm{~mm}$ diameter pilot one suggested by the provider. 
In the same way, a $4 \mathrm{~mm}$ diameter pilot hole was preferred for bricks instead of the $5 \mathrm{~mm}$ one suggested by the provider [8].

The procedure for HPT is executed as follows. A pilot hole of $3 \mathrm{~mm}$ diameter is made in the mortar joints with a drill working at the minimum speed and with the tightening power adjusted at the weakest position. A pilot hole of $4 \mathrm{~mm}$ diameter is made in the bricks using a rotaryhammer drill with a masonry bit (Figure 2a). A high-strength steel helical tie with a diameter of $1 / 4$ in. $(6.3 \mathrm{~mm})$ is mounted into a supplementary tool. While holding it horizontally, the tool is hammered carefully until the helical tie is introduced into the pilot hole to a depth of $30 \mathrm{~mm}$ and results embedded in the masonry component (Figure $2 \mathrm{~b}$ ). This process allows the helical tie to rotate and cut a thread in the mortar or the unit during insertion. After insertion, a Load Test Key (LTK) is screwed onto the remaining outer part of the tie. The LTK restrains from rotating the helical tie during the test, assuring a shear failure in the tested material. The Load Test Unit (LTU) is connected to the LTK and the mechanism is rotated to screw down the tie and take up any slack. The LTU provides the contact with the material's surface by means of a steel circle. The load is applied by turning a grip lever to increase progressively the load until failure (Figure 2c). The maximum load reached during the test is recorded as the pull-out force. Figure 2 shows the test layout, as well as the sequence of the operations during the HPT.

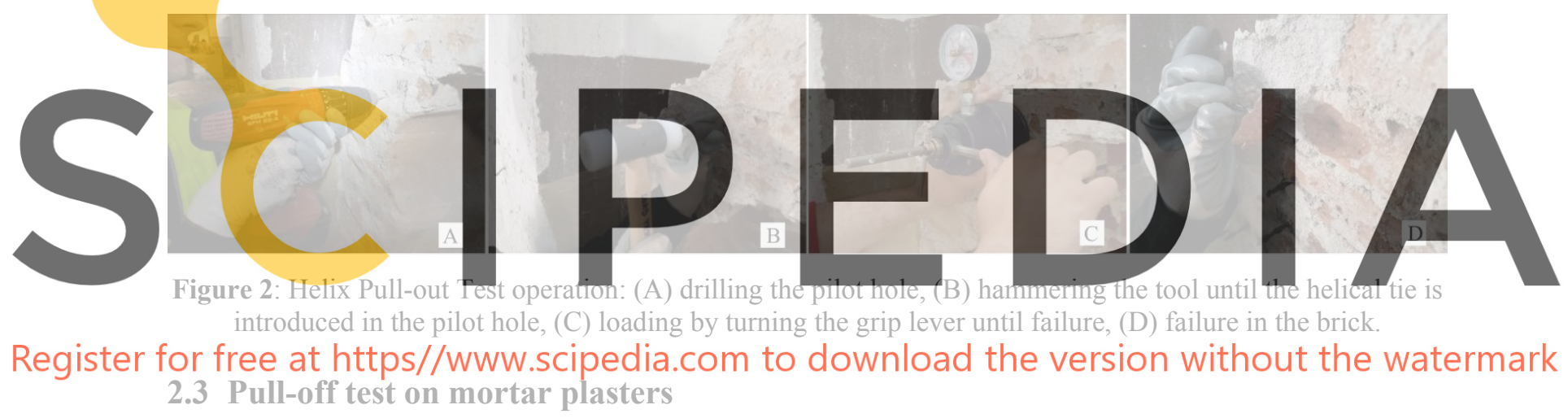

The puil-off test (POT) is a test deveioped to evaluate the adhesion strength of gypsum and lime mortar plasters [9]. The POT was executed on lime mortar plasters in the investigated building. Figure 3 shows the sequence of operations of the experimental in-situ tests. The first operation consists in removing the surface paint layer with a mechanical sanding that does not alter the physical and chemical characteristics of the lime mortar and ensures proper adhesion (Figure 3a). The plaster is cut until reaching the masonry substrate by using a core bit with 50 $\mathrm{mm}$ diameter (Figure 3b). After notching a number of circles, $50 \mathrm{~mm}$ diameter metal discs are stuck to the coating with a two components adhesive consisting of methylmetacrylate (Figure $3 \mathrm{c})$. Once the adhesive has hardened, the disc is pulled off with a dynamometer by applying a perpendicular force to the surface. Two different dynamometers were used. A manual reaction dynamometer with a capacity of $500 \mathrm{~N}$ and a digital accuracy of $0.1 \mathrm{~N}$ was used in the position ZA. This position was characterised by lower adhesion strength (Figure 3d). In zones with higher adhesion strength, a different device with a mechanical dynamometer support, capacity of $5000 \mathrm{~N}$ and manual reading was used (Figure 3e). The pull-off load applied to the metal disc 
is increased steadily until failure (Figure 3f). The peak load reached during each test is recorded as the pull-off strength.

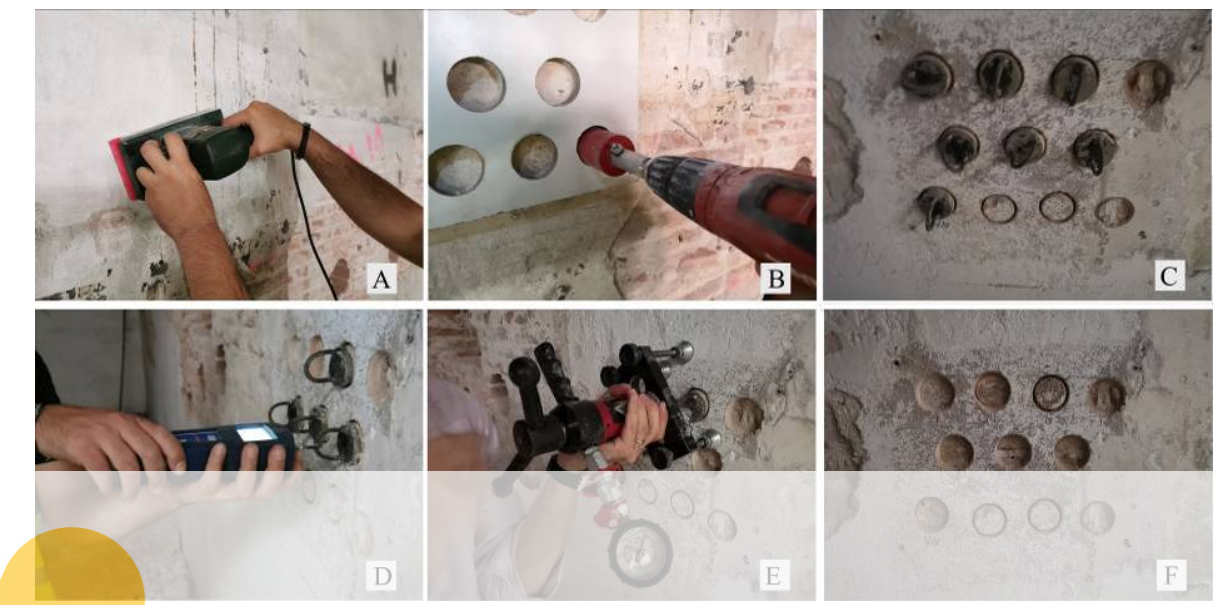

Figure 3: Pull-off test operation: (A) removing the surface paint layer with a mechanical sanding, (B) drilling the plaster until reaching the masonry substrate using a $50 \mathrm{~mm}$ diameter core bit, (C) sticking the metal discs,

(D) manual dynamometer, (E) mechanical dynamometer support, and (F) failure of plaster substrate.

\subsection{Extractions of the \\ The masonry walls investigated were 450 \\ units with nominal size 295. \\ variable between $12 \mathrm{~nm}$ and 18 . \\ The extractions of \\ he CDM \\ samples were done

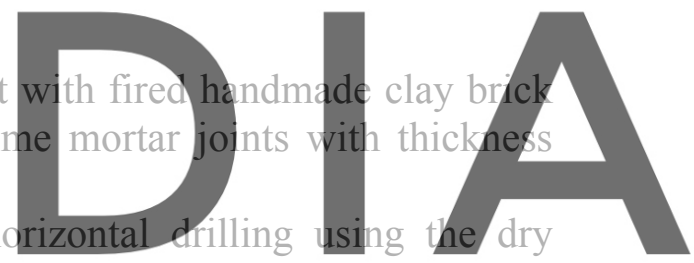

technology proposed in [6]. Figure 4 shows the sequence of operations of the in-situ extractions.

Register fBeffre drillin a

including one vertical and two horizontal mortar joints and four bricks (Figure 4a). Twenty-one

specimens were drilled in five extraction zones (Figure 4b and c). Only three out of twenty-one

specimens were discarded after the extraction operations due to irregularities inside the wall.

All the CDM samples had an approximate depth of $300 \mathrm{~mm}$ and were cut in the laboratory using a dry radial saw in order to obtain an approximate depth of $145 \mathrm{~mm}$ (Figure 4d). After drilling, some courses of the wall were disassembled using a chisel and a hammer to extract whole bricks and mortar joints. The selected specimens were stored and labelled carefully to preserve their integrity until taken to the laboratory.

The timbrel vaults of the industrial building were composed of two layers of fired handmade clay tiles. Their bond was staggered through the thickness of the vault in order to prevent the alignment of the tile joints. The components used in the vaults were tiles with nominal size of $294.3 \times 145.3 \times 20.8 \mathrm{~mm}^{3}$. The lime mortar joints had thickness of $17 \mathrm{~mm}$ in the $1^{\text {st }}$ timbrel vault and of $10 \mathrm{~mm}$ in the $2^{\text {nd }}$ timbrel vault.

Figure 5 shows the sequence of operations of the in-situ extractions, executed from the top of the timbrel vaults by removing first the pavements and then the vault filling (Figure 5a). The 
mortar joints between tiles were marked with a radial saw (Figure 5b) and then extracted carefully with a chisel and a gauging trowel (Figure $5 \mathrm{c}$ and d).
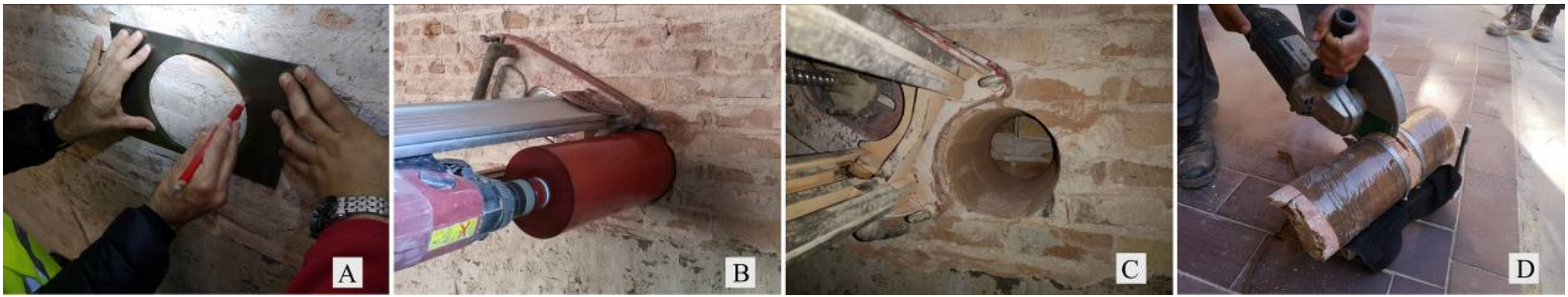

Figure 4: The sequence of operations of the cylinder extractions: (A) marking the core perimeter before extraction, (B) drilling, (C) hole in the wall after extraction, (D) cutting the specimen with a dry radial saw until obtaining an approximate depth of $145 \mathrm{~mm}$.
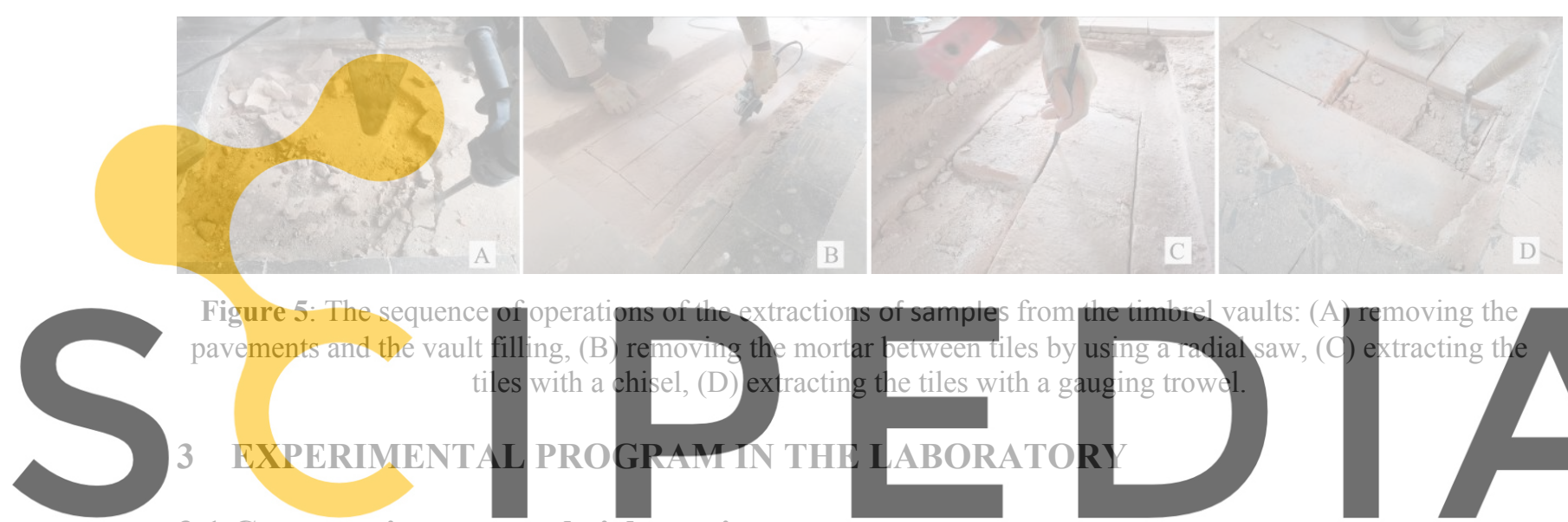

Figure 5: The sequence o pavements and the vault fill

\section{EXPERIMIENTA}
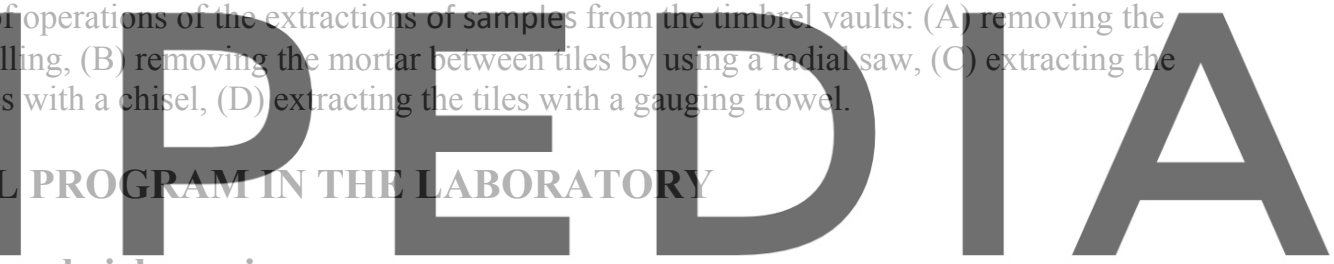

\subsection{Compressive tests on brick specimens}

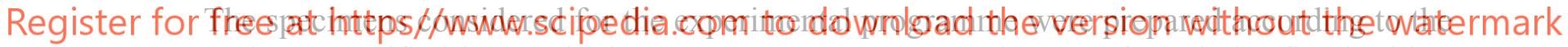
procedures specified in standard EN 772-1:2011+A1 [4]. The use of a grinder fitted with a diamond-impregnated head could guarantee the flatness and parallelism of the faces. The specimens were cut from the bricks using a table saw equipped with a water jet, and air conditioned in a dry mode at a constant temperature of $105^{\circ} \mathrm{C}$. Two types of specimens were obtained from every extraction zone, i.e. a specimen measuring $100 \times 100 \times 40 \mathrm{~mm}^{3}$ (identified as "CB_10") fulfilling the standard requirements, and $40 \times 40 \times 40 \mathrm{~mm}^{3}$ cubes (identified as "CB_C 4 ") as a nonstandard size that allows a considerable increase of the number of available samples.

The specimens were tested under uniaxial compression by using two hydraulic testing machines, with a capacity of $3000 \mathrm{kN}$ for CB_10 specimens, and a capacity of $200 \mathrm{kN}$ for CB_C4 samples. The tests were executed under load control with a rate of $0.15 \mathrm{MPa} / \mathrm{s}$ with duration of the test higher than 60 seconds. 


\subsection{Compressive tests on tile specimens}

The characterization of the clay tiles from the timbrel vaults is not possible according to the European standard EN 772-1:2011+A1 [4] or American ASTM C67 [10] due the reduced thickness of the units. To overcome this problem, the proposed solution consisted in assembling two specimens with a cement mortar layer allowing the connection between the samples. This strategy allowed the reduction of the slenderness of the specimen (Figure 6a).

The specimens were cut from the clay tile using a table saw. Two specimens were obtained for every clay tile measuring $100 \times 100 \times t \mathrm{~mm}^{3}$, were $t$ is the thickness of the specimen (identified as "CB-F"). These two specimens were assembled using a mould designed and built specifically for this research. The cement mortar was kept $10 \mathrm{~mm}$ away from the contact with the testing machine plates. The specimens were grinded on loaded faces to ensure a uniform distribution of compression forces (Figure 6b). The specimens were tested under uniaxial compression using a hydraulic testing machine with a capacity of $200 \mathrm{kN}$. The loading rate under displacement control was $0.025 \mathrm{~mm} / \mathrm{s}$ to ensure a duration of the test higher than 60 seconds (Figure 6d).

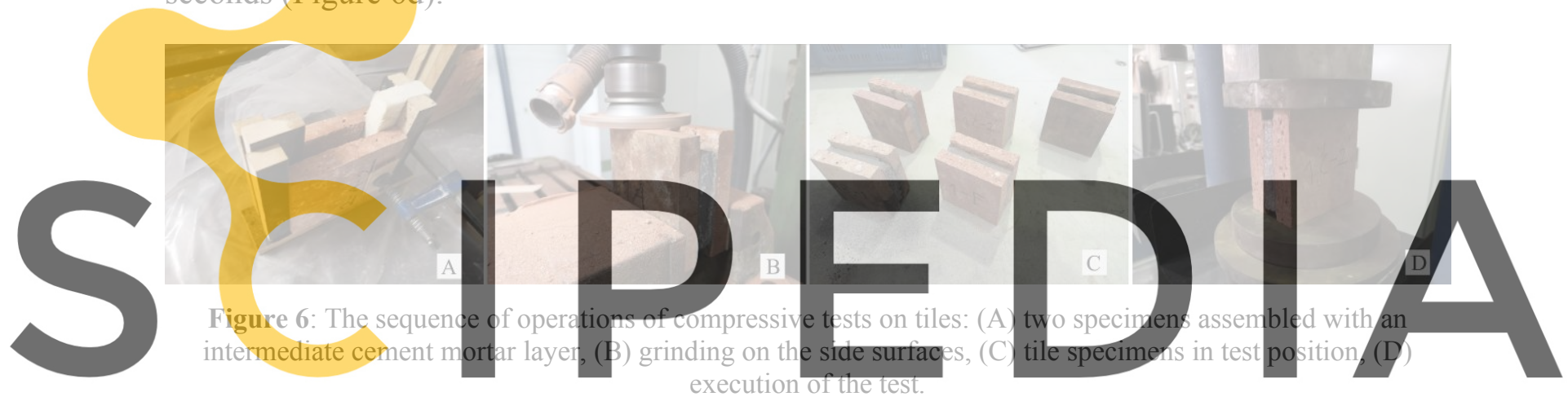

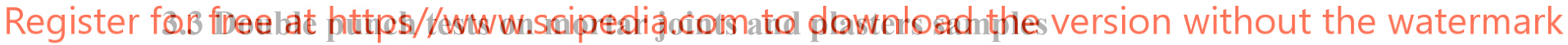

The mortar bed joints extracted between the units, as well as the plaster samples, had low consistency and cohesion. This fact, usual in historical structures, made the preparation of regular specimens difficult. For this reason, it was not possible to test mortar slabs with exact dimensions of $50 \times 50 \mathrm{~mm}^{2}$ as recommended by the German standard DIN 18555-9 [5]. A gypsum powder layer with a thickness of $1 \mathrm{~mm}$ was interposed between the specimen and the loading punches, which had a diameter of $20 \mathrm{~mm}$.

The specimens were tested under uniaxial compression using a hydraulic testing machine with a capacity of $10 \mathrm{kN}$. The loading rate under load control ensured that the test would last approximately 60 seconds. After the DPT, the specimens showed a crushed central part shaped like a sandglass between the loading punches and radial cracks toward the outer perimeter.

\subsection{Compressive strength of core drilled specimens}

Once brought to the laboratory, two high strength mortar caps were casted on top and bottom of the CDM cores by using a special mould. The mortar caps created two flat surfaces allowing a distributed load, as proposed in [6] and [7] and unlike the UIC leaflet [11] recommendation 
on the use of steel concave plates and lead sheets in contact with the sample. The sizes of the caps were about $110 \mathrm{~mm}$ width and $150 \mathrm{~mm}$ length.

The specimens were tested under uniaxial compression using a hydraulic testing machine with a capacity of $3000 \mathrm{kN}$. The force was applied perpendicularly to the horizontal joints. The tests were carried out in two stages. The first stage was oriented to the study of the elastic behaviour of the masonry and consisted in the application of three loading/unloading cycles under load control ranging from $5 \%$ to $20 \%$ of the estimated maximum load. Its value was determined by using the expression proposed by the Eurocode 6 (EC6) [12] to obtain the characteristic compressive strength of masonry, $f_{c}$, using the normalised compressive strength of the units, $f_{b}$, and the mortar, $f_{m}$. The Young's modulus was calculated for the loading branch of the third cycle. The second stage of the test was aimed to characterize the compressive strength of masonry. The cylinders were tested under displacement control, at a rate of 0.004 $\mathrm{mm} / \mathrm{s}$. The compressive strength was calculated as the ratio between the maximum load and the cross-section of the mortar caps [13].

\section{DISCUSSION OF THE RESULTS}

\subsection{Summary of in-situ and laboratory experimental results}

Table 1 reports a summary of the in-situ experimental results on mortar joints (MJ), bricks

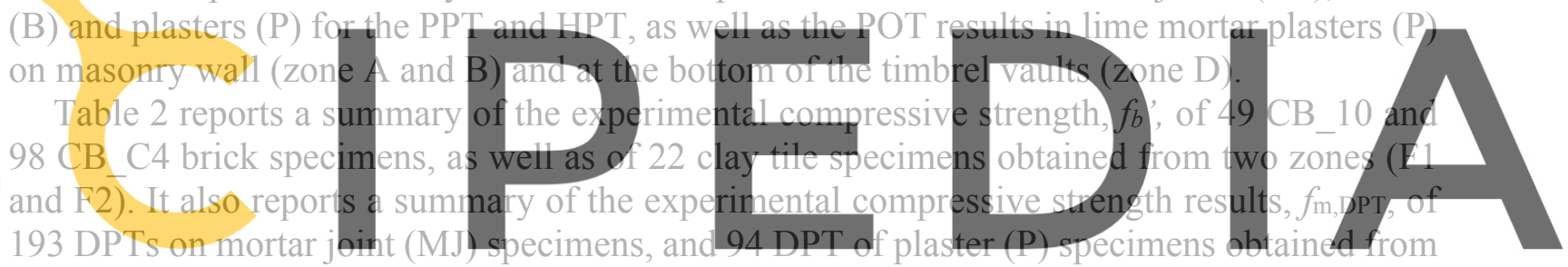
the different zones. Finally, Table 2 presents the values of the experimental compressive

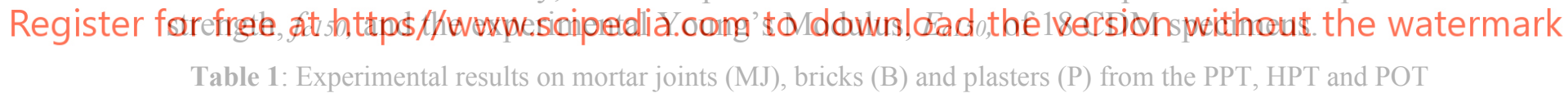
tests, in terms of the average values (Av) and coefficients of variation (CV), for six zones of masoniry walls ( $Z 1$, Z2, Z2bis, Z3, Z4 and Z5) and four zones of plasters (ZA, ZB, ZC and ZD).

\begin{tabular}{|c|c|c|c|c|c|c|c|c|c|c|c|}
\hline & & $\mathbf{Z 1}$ & $\mathbf{Z 2}$ & Z2bis & $\mathbf{Z 3}$ & $\mathbf{Z 4}$ & $\mathbf{Z 5}$ & $\mathbf{Z A}$ & $\mathbf{Z B}$ & $\mathbf{Z C}$ & ZD \\
\hline & & \multicolumn{10}{|c|}{ Lime Mortar Joints $(M J) /$ Plasters $(P)$} \\
\hline \multirow{2}{*}{$\begin{array}{c}\text { PPT } \\
{[\mathrm{mm}]}\end{array}$} & Av & 10.4 & 10.6 & 10.4 & 11.3 & 10.4 & 9.8 & 9.9 & 7.4 & 5.6 & 7.0 \\
\hline & $\mathrm{CV}$ & $4.5 \%$ & $4.8 \%$ & $4.3 \%$ & $7.7 \%$ & $8.3 \%$ & $5.9 \%$ & $8.4 \%$ & $15.2 \%$ & $8.2 \%$ & $9.5 \%$ \\
\hline \multirow{2}{*}{$\begin{array}{c}\text { HPT } \\
{[\mathrm{N}]}\end{array}$} & Av & 415 & 405 & 455 & 531 & 435 & 765 & - & - & - & - \\
\hline & $\mathrm{CV}$ & $35.5 \%$ & $34.3 \%$ & $24.0 \%$ & $33.3 \%$ & $18.0 \%$ & $20.0 \%$ & - & - & - & - \\
\hline \multirow{3}{*}{$\begin{array}{c}\text { POT } \\
{[\mathrm{N}]}\end{array}$} & Av & - & - & - & - & - & - & 77 & 295 & - & 350 \\
\hline & $\mathrm{CV}$ & - & - & - & - & - & - & $38.6 \%$ & $94.4 \%$ & - & $49.5 \%$ \\
\hline & & \multicolumn{10}{|c|}{ Fired Handmade Clay Brick (B) } \\
\hline \multirow{2}{*}{$\begin{array}{c}\text { PPT } \\
{[\mathrm{mm}]}\end{array}$} & Av & 6.6 & 6.2 & 5.9 & 5.8 & 5.9 & 6.0 & - & - & - & - \\
\hline & $\mathrm{CV}$ & $23.6 \%$ & $13.3 \%$ & $16.7 \%$ & $11.3 \%$ & $11.6 \%$ & $15.2 \%$ & - & - & - & - \\
\hline \multirow{2}{*}{$\begin{array}{c}\text { HPT } \\
{[\mathrm{N}]}\end{array}$} & Av & 1700 & 2005 & 1665 & 1625 & 1795 & 1670 & - & - & - & - \\
\hline & $\mathrm{CV}$ & $14.1 \%$ & $13.7 \%$ & $9.2 \%$ & $16.5 \%$ & $20.2 \%$ & $10.3 \%$ & - & - & - & - \\
\hline
\end{tabular}


Table 2: Experimental compressive strength averages values (Av) and coefficients of variation (CV) on brick specimens (CB_10, CB_C4), tile specimens (CB_F1, CB_F2), mortar joint specimens (MJ), plaster specimens (P) and Core Drilled Masonry (CDM) samples obtained on six extraction zones of masonry wall (Z1, Z2, Z2bis, Z3, Z4 and Z5), on two extraction zones of timbrel vaults (F1 and F2) and on t five extraction zones of plasters, three from wall (ZA, ZB and ZC) and two from the bottom of the timbrel vaults (ZD and ZE).

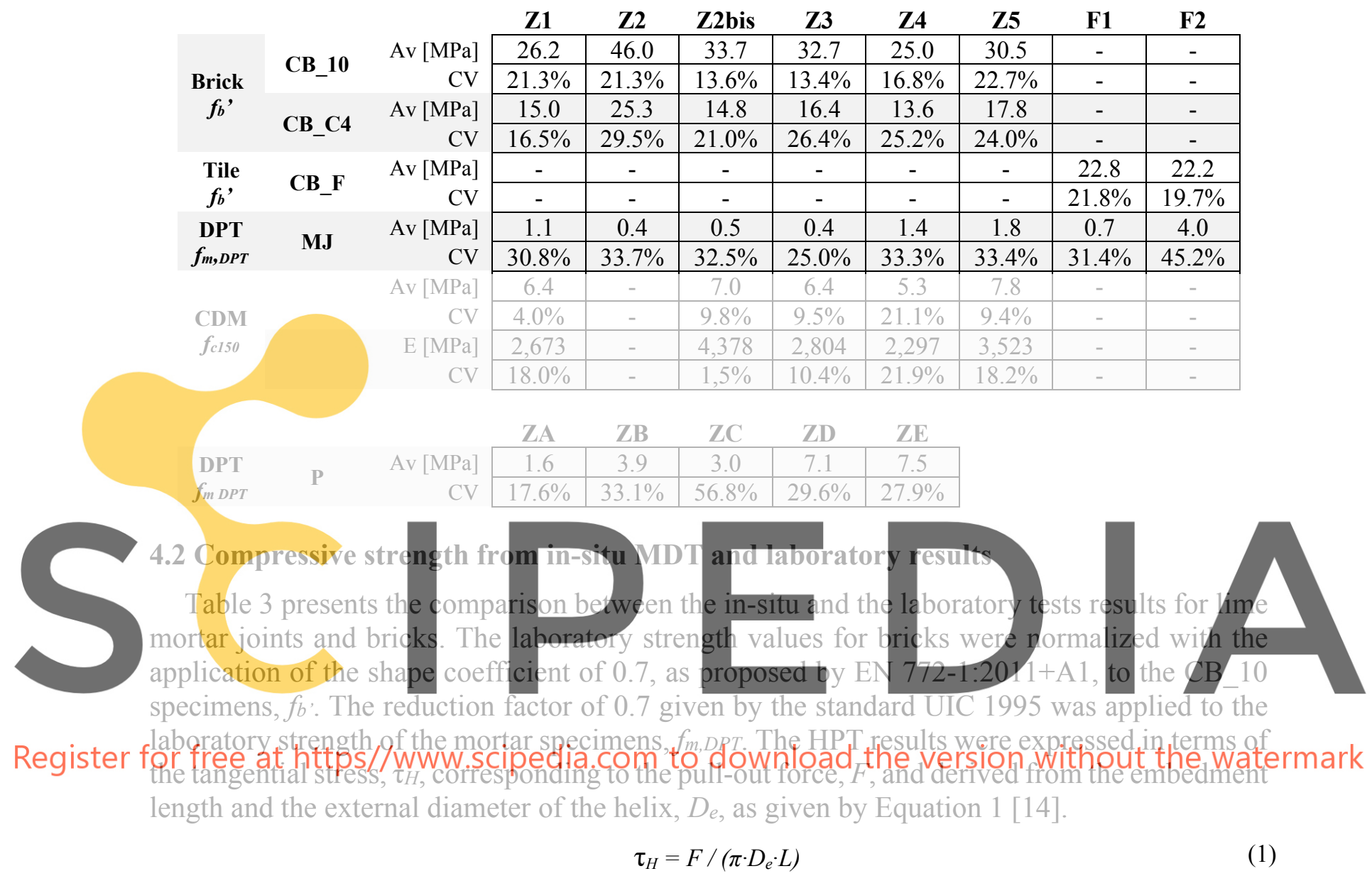

The variation trends of HPT results in terms of pull-out forces are fairly consistent with ranges of variations of the depth measurements obtained with PPT, as well as strengths derived from DPT for lime mortars. The HPT allowed the identification of significant in mortar performance except in the Z5 zone. The PPT showed the same result, with Z5 exhibiting a higher resistance to penetration. The variation trends of the PPT also showed good agreement with the DPT in plasters (ZA, ZB and ZC).

It is worth to mention that HPT and PPT on tested mortars provided a better agreement between them than with the DPT values. This disagreement is attributed to the fact that the specimens were dried and better conditioned when brought to the laboratory and therefore had a different moisture contents compared to the mortars in their original location. As for the bricks, the HPT and PPT values were very close to each other in spite of the variations of the 
laboratory compressive strengths, not allowing to identified a clear relationship between on site and laboratory results.

Figure 7a shows the comparison between the HPT results and the laboratory results for this campaign, together with those reported in previous research studies by Pelà et al. [2] and de Vekey et al. [8]. Figure $7 \mathrm{~b}$ shows the same results for bricks tested in this campaign, together with literature values of units of compressive strength over $10 \mathrm{MPa}$ according to Ferguson [15]. The HPT on mortars provides a good relationship with the laboratory values for this campaign, as well as with the values reported in the previous researches, especially for low strengths. However, the case of bricks no clear relationship is obtained between HPT and compressive strength test as already observed by Ferguson [15]. As explained by de Vekey et al. [8], the stress could exceed the elastic limit of the tie when the material tested had a compressive strength over $10 \mathrm{MPa}$. Actually, reliable relationships for historical masonry constituents are still under investigation.
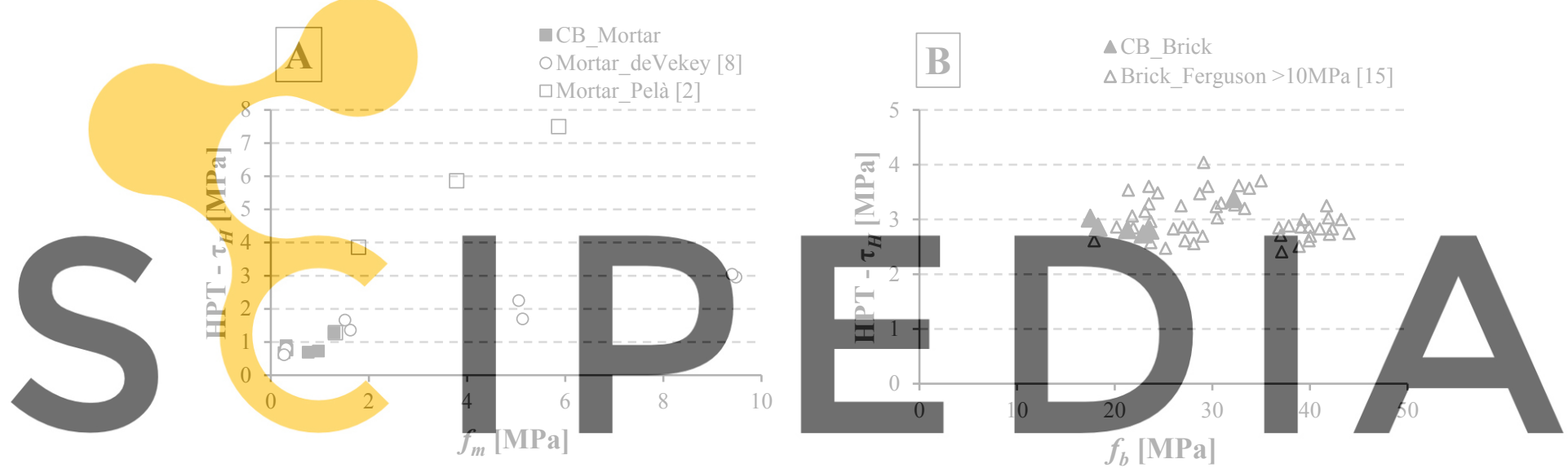

Register for free at https//www.scipedia.com to download the version without the watermark Figure 7: (A) Tangential stress of HPT on mortar joints compared with Pelà et al. [2] and de Vekey et al. [8] values. (B) Tangential stress of HPT on bricks compared with Ferguson values [15].

Table 3: Comparison among in-situ MDT and laboratory results on lime mortar joints, bricks and lime plasters.

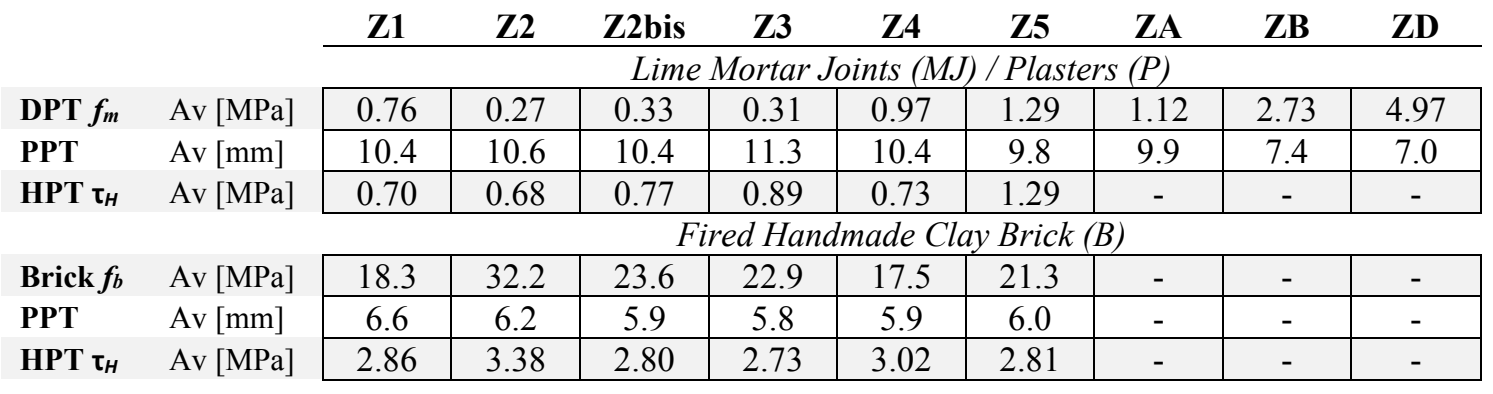

\subsection{Relationship between CB_10 and CB_C4 brick specimens}

Another stage of the experimental campaign considered compression tests on nonstandard specimens measuring $40 \times 40 \times 40 \mathrm{~mm}^{3}$, CB_C4. The average values of experimental 
compressive strengths of the CB_C4 samples $\left(f_{b} C 4\right)$ have been related with the standard CB_10 ones $\left(f_{b} 10\right)$. Table 4 reports the ratio between the uniaxial compressive strengths $\left(f_{\mathrm{b}_{-}} \mathrm{C}_{10} / f_{\mathrm{b}} \mathrm{C} 4\right)$. The given ratios resulted between 1.71 and 2.28. In average, the $f_{b_{-}} 10$ strength was equal to 1.90 $f_{b}$ C4 with CV equal to $11 \%$.

Table 4: The relationship between the experimental compressive strength of the nonstandard specimen CB_C4 and the standard specimen CB_10.

\begin{tabular}{|c|c|c|c|c|c|c|c|c|c|}
\hline & & & $\mathrm{Z1}$ & $\mathbf{Z 2}$ & Z2bis & $\mathbf{Z 3}$ & $\mathbf{Z 4}$ & $\mathbf{Z 5}$ & \\
\hline \multirow{3}{*}{ Brick } & CB_10 & $\mathrm{Av}[\mathrm{MPa}]$ & 26.2 & 46.0 & 33.7 & 32.7 & 25.0 & 30.5 & \multirow{3}{*}{$\begin{array}{c}\text { Average } \\
1.90[C V 11 \%\end{array}$} \\
\hline & CB_C4 & $\mathrm{Av}[\mathrm{MPa}]$ & 15.0 & 25.3 & 14.8 & 16.4 & 13.6 & 17.8 & \\
\hline & \multicolumn{2}{|c|}{$f_{b} C B_{-} 10 / f_{b} C B_{-} C 4$} & 1.74 & 1.82 & 2.28 & 1.99 & 1.84 & 1.71 & \\
\hline
\end{tabular}

\subsection{Evaluation of masonry compressive strength from available analytical equations}

The characteristic compressive strengths of masonry, $f_{c}$, has been evaluated from the experimental average compressive strengths, $f_{c_{-}} \exp$, and the empirical equation provided by Eurocode 6 [12], $f_{C_{-} E C 6}$, and American Requirements for Masonry Structures (ACI 530.1-05) $[16], f_{C \_A C T}$. The characteristic $f_{c_{-} \text {exp }}$ values were calculated according to the procedures described in EN 1052-1 [17] using the CDM experimental values, $f_{c 150}$. Accordingly, the $f_{c 150}$ values have been divided by 1.2 for inspection zones with less than five specimens. The $f_{c_{-}} \exp$ corresponded to the $5 \%$ fractile value based on a confidence level of $95 \%$ if there were five or more

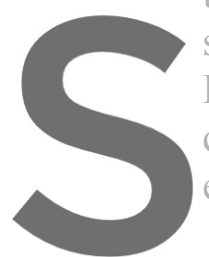
Specimens. The $f_{C} E C$ and $f_{c} A C I$ were obtaine
Eurocode 6 relates the characteristic compres
compressive strength of brick, $f_{b}$, and nottar,
equation relates it to the compressive strength
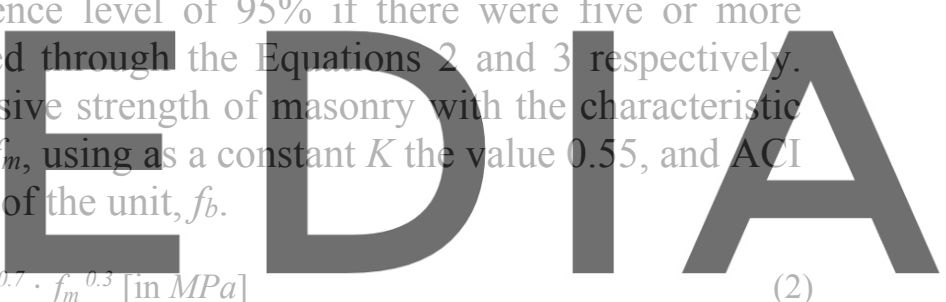

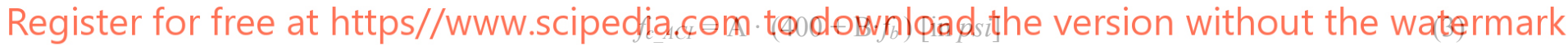

The Young's modulus of masonry, $E_{c}$, has been also analysed. The Eurocode 6 suggests that $E_{c_{-} E C 6}$ is 1000 times the compressive strength, while ACI 530.1-05, $E_{c_{-} A C I}$ suggests that is 700 times the compressive strength. The experimental values of Young's modulus, $E_{c_{-} \text {exp }}$, were obtained as explained in Section 3.4 testing the CDM specimens.

Table 5 reports a summary of the experimental and empirical evaluations of the masonry compressive strength and Young's modulus. The Eurocode 6 provides values lower than the experimental ones, while the ACI 530.1-05 results are higher than the experimental ones. The only good agreement between laboratory and analytical evaluations has been found for specimens of zone Z4 for EC6 equation, and of zone Z5 for the ACI equation. Previous research [18] provided good relationships between the empirical and experimental strengths for lime mortars with $2 \mathrm{MPa}$ strength. Table 5 also presents that the Young's modulus estimated from the standards is overestimated compared with the experimental ratios $E_{c} / f_{c}$ ranging between 475 and 759. 
Table 5: Experimental and empirical compressive strengths, $f_{c}(\mathrm{MPa})$ and Young's moduli, $E_{c}(\mathrm{GPa})$.

\begin{tabular}{|c|c|c|c|c|c|c|}
\hline & & Z1 & Z2bis & $\mathbf{Z 3}$ & Z4 & Z5 \\
\hline \multirow{3}{*}{$\begin{array}{l}\text { Masonry } \\
f_{c}[\mathrm{MPa}]\end{array}$} & $f_{\text {c_exp }}$ & 5.4 & 5.9 & 5.9 & 4.4 & 7.2 \\
\hline & $f_{c \_E C 6}$ & 3.9 & 3.6 & 3.4 & 4.0 & 5.0 \\
\hline & $f_{c \_A C I}$ & 6.4 & 7.5 & 7.3 & 6.2 & 7.0 \\
\hline \multirow{3}{*}{$\begin{array}{l}\text { Masonry } \\
\boldsymbol{E}_{\boldsymbol{c}}[\mathrm{GPa}]\end{array}$} & $E_{c \_ \text {exp }}$ & 2.7 & 4.4 & 2.8 & 2.3 & 3.5 \\
\hline & $E_{c_{-} E C 6}$ & 3.9 & 3.6 & 3.4 & 4.0 & 5.0 \\
\hline & $E_{c_{-} A C I}$ & 4.5 & 5.2 & 5.1 & 4.4 & 4.9 \\
\hline \multicolumn{2}{|c|}{$E_{c \_\exp } / f_{c \text { exp }}$} & 500 & 759 & 475 & 523 & 486 \\
\hline
\end{tabular}

\section{CONCLUSIONS}

This paper has presented the experimental results from in-situ and laboratory minor destructive testing (MDT) of the masonry materials of an industrial $19^{\text {th }} \mathrm{c}$. building of Barcelona. Tests on samples made possible to determine the compressive strengths of bricks, tiles, mortars and masonry.

The following conclusions can be drawn from the research:

- The laboratory testing on novel types of specimen shows consistent results. In particular, the research proposes a novel methodology for the characterisation of the thin-tile of timbrel vaults.

- Tests on the nonstandard $40 \times 40 \times 40 \mathrm{~mm}^{3}$ brick specimens showed similar scattering than the standard $100 \times 100 \times 40 \mathrm{~mm}^{3}$ ones. Moreover, a clear correlation could be found between the compressive strength obtained with the two specimens. However, further investigation should be done to analyse the influence of the specimen size and shape on the compressive strength.

- The empirical equations provided by the building codes yielded values that overestimated or underestimated the compressive strength obtained from the extracted cylindrical cores.

- The in-situ MDTs have provided clear correlation trends in the evaluation of the mortar strength. In particular, and for the case of mortars, the sufficient sensitivity of HPT and PPT test allow the possibility of relating their results with experimental laboratory values.

- The in-situ MDT results for the evaluation of the clay bricks still do not show sufficient sensitivity to the variation of the material strength. More research is necessary in order to improve the application of HPT and PPT for a more reliable in-situ characterization of bricks.

Acknowledgements. The authors gratefully acknowledge the financial support from the Ministry of Science, Innovation and Universities of the Spanish Government (MCIU), the State Agency of Research (AEI) as well as that of the ERDF (European Regional Development Fund) through the project SEVERUS (Multilevel evaluation of seismic vulnerability and risk mitigation of masonry buildings in resilient historical urban centres, ref. Num. RTI2018099589-B-I00). Support from MCIU through a predoctoral grant awarded to the first author is also gratefully acknowledged. 


\section{REFERENCES}

[1] A. W. Hendry, Structural Masonry. London: Macmillan Education UK, (1998).

[2] L. Pelà, P. Roca, and A. Aprile, "Combined In-Situ and Laboratory Minor Destructive Testing of Historical Mortars," Int. J. Archit. Herit., vol. 12, no. 3, (2018), pp. 334-349.

[3] European Committee for Standardization (CEN), "EN 1015-12 Methods of test for mortar for masonry - Part 12: Determination of adhesive strength of hardened rendering and plastering mortars on substrates." (2016).

[4] European Committee for Standardization (CEN), "EN 772-1+A1 Methods of test for Masonry Units - Part 1: Determination of Compressive Strength." (2016).

[5] Deutsche Norm, "DIN 18555-9 Testing of mortar containing mineral binders - Part 9: Determining the compressive strength of hardened mortar." (1999).

[6] L. Pelà, E. Canella, A. Aprile, and P. Roca, "Compression test of masonry core samples extracted from existing brickwork," Constr. Build. Mater., vol. 119, (2016), pp. 230-240.

[7] J. Segura, L. Pelà, P. Roca, and A. Cabané, "Experimental analysis of the size effect on the compressive behaviour of cylindrical samples core-drilled from existing brick masonry," Constr. Build. Mater., vol. 228, (2019), p. 116759.

[8] R. C. de Vekey and M. Sassu, "Comparison of non-destructive in-situ mechanical test on masonry mortars: The PNT-G method and the helix method," in Proceedings of the 11th international brick and block masonry conference (IB2MC), (1997), pp. 376-384.

[9] M. L. Tavares, M. R. Veiga, and A. Fragata, "Grouting mortars for consolidation of historical renders showing loss of adhesion," in 2nd Conference on Historic Mortars - HMC 2010 and RILEM TC 203-RHM final workshop, (2010), pp. 743-752.

[10] American Society for Testing and Materials (ASTM), "C67-18 Standard Test Methods for Sampling and Testing Brick and Structural Clay Tile." (2005).

[11] UIC, "Leaflet 778-3R: Recommendations for the inspection, assessment and maintainance of masonry arch bridges." UIC - International Union of Railways, Paris, France, (1995).

[12] European Committee for Standardization (CEN), "EN 1996-1-1 Design of masonry structures Part 1-1: General rules for reinforced and unreinforced masonry structures." (2005).

[13] L. Pelà, S. Saloustros, and P. Roca, "Cylindrical samples of brick masonry with aerial lime mortar under compression: Experimental and numerical study," Constr. Build. Mater., vol. 227, no. September, (2019), p. 116782.

[14] A. Benedetti and M. Tarozzi, "Interpretation formulas for in situ characterization of mortar strength," Constr. Build. Mater., vol. 242, (2020), p. 118093.

[15] W. A. Ferguson and J. Skandamoorthy, "The screw pull-out test for the in-situ measurement of the strength of masonry materials," in Proceedings of the 10th international brick and block masonry conference, (1994), pp. 1257-66.

[16] Masonry Standards Joint Committee (MSJC), "Specification for Masonry Structures (ACI 530.105/ASCE 6-05/TMS 602-05)." (2004).

[17] European Committee for Standardization (CEN), "EN 1052-1 Methods of test for masonry - Part 1 : Determination of compressive strength." (1999).

[18] J. Segura, L. Pelà, and P. Roca, "Monotonic and cyclic testing of clay brick and lime mortar masonry in compression," Constr. Build. Mater., vol. 193, (2018), pp. 453-466. 